\section{A construção modal deôntica necesitar+infinitivo: uma análise discursivo-funcional em língua espanhola}

The deontic modal construction necesitar+infinitivo: $a$ discursive-functional analysis in the Spanish language

André Silva OLIVEIRA (PPGL/UFC) andrethtzn@gmail.com

Recebido em: 10 de set. de 2020. Aceito em: 12 de out. de 2020.
OLIVEIRA, André Silva. A construção modal deôntica necesitar+infinitivo: uma análise discursivo-funcional em língua espanhola. Entrepalavras, Fortaleza, v. 11, n. 2, e2078, p. 1-21, maio-ago./2021. DOI: 10.22168/22376321-22078.

Resumo: Esta pesquisa tem por objetivo analisar o comportamento da construção necesitar+infinitivo como forma de expressão da modalidade deôntica em língua espanhola, considerando que o operador modal necesitar possa expressar obrigação (necessidade deôntica). Nesse sentido, recorre-se à Gramática Discursivo-Funcional (GDF) de Hengeveld e Mackenzie (2008), no intuito de identificar a atuação dessa construção nas camadas que compõem o Nível Representacional, na qual estão alocadas as distinções modais. Para isso, são analisados diferentes usos dessa construção perifrástica em amostras de língua que foram retiradas da Internet, tais como notícias, blogs, fóruns de debate, websites de faculdades e universidades, etc., e produzidas por falantes nativos de espanhol. A seleção pelas amostras foi feita, especificamente, com base em contextos de instauração de modalidade deôntica, que, segundo Hengeveld (2004), diz respeito ao que é moralmente, legalmente e socialmente aceito em termos de regras e normas de conduta. A análise das ocorrências, apoiada na GDF, revela que a construção necesitar+infinitivo pode atuar, na instauração da modalidade deôntica, 
V. $11(2)$

1-21 maio-ago 2021

nas camadas da Propriedade Configuracional e do Estado-de-Coisas, instaurando os valores modais de obrigação (polaridade positiva) e derrogação (polaridade negativa), cujos sujeitos sintáticos podem ser animados ou inanimados. Para além do que é predisposto pela GDF, foi verificado que essa construção perifrástica pode operar também na camada do Episódio, em que o falante faz uma avaliação subjetiva sobre a obrigatoriedade de realização de um evento localizado em um momento anterior ao da enunciação, podendo este evento ser reatualizado pelo participante sobre quem recai a obrigação instaurada.

Palavras-chave: Gramática Discursivo-Funcional. Modalidade Deôntica. Língua Espanhola.

Abstract: This research aims to analyze the behavior of the construction necesitar+infinitive as a way of expressing the deontic modality in Spanish, considering that the modal operator needs to express obligation (deontic need). In this sense, we use the Functional Discourse Grammar (FDG) of Hengeveld and Mackenzie (2008), in order to identify the performance of this construction in the layers that make up the Representational Level, in which the modal distinctions are allocated. For this, different uses of this periphrasis structure are analyzed in language samples that were taken from the Internet, such as news, blogs, discussion forums, college and university websites, etc., and produced by native Spanish speakers. The selection by the samples was made, specifically, based on contexts of establishment of deontic modality, which, according to Hengeveld (2004), concerns what is morally, legally and socially accepted in terms of rules and standards of conduct. The analysis of the occurrences, supported by the GDF, reveals that the construction necesitar+infinitive can act, in the establishment of the deontic modality, in the layers of Configurational Property and the State-of-Affairs, establishing the modal values of obligation (positive polarity) and derogation (negative polarity), whose syntactic subjects can be animated or inanimate. In addition to what is predisposed by the FDG, it was found that this peripheral construction can also operate in the Episode layer, in which the speaker makes a subjective assessment of the obligation to hold an event located before the enunciation, which can be event to be updated by the participant on whom the established obligation falls.

Keywords: Functional Discourse Grammar. Deontic Modality. Spanish Language.

\section{Introdução}

Acreditando que o operador modal necesitar possa instaurar o valor modal de obrigação (necessidade deôntica) em língua espanhola, o objetivo desta pesquisa ${ }^{1}$ consiste em analisar a atuação da construção perifrástica necesitar+infinitivo nas camadas que compõem o Nível Representacional. Ao operar nesse nível, essa construção perifrástica instaura modalidade deôntica, que, segundo Hengeveld (2004), diz respeito ao que é moralmente, legalmente e socialmente aceito em termos de regras e normas de conduta.

É possível perceber que essa construção parece ser bem produtiva em espanhol no que tange à instauração de necessidade deôntica (obrigação), como se pode constatar nas ocorrências (1) e (2):

${ }^{1}$ O presente trabalho foi realizado com apoio da Coordenação de Aperfeiçoamento de Pessoal de Nível Superior - Brasil (CAPES) - Código de Financiamento 001. 
(1) Ud. necesita ayudar con la recuperación de su personal también. Una reunión posterior a la emergencia es esencial para permitir que su gente se desahogue y para asegurarse de entender qué pasó para poder mejorar su servicio la próxima vez. Porque habrá una próxima vez. ${ }^{2}$

(2) "Se necesita trabajar a diario en la prevención del riesgo de desastres, de lo contrario no conseguiremos prosperar. Esta tarea puede tomar muchos años, pero no los tenemos y hemos de trabajar con rapidez y conjuntamente para conseguirlo" Mami Mizutori. ${ }^{3}$

Em (1), o sujeito sintático do modal necesitar se trata de um sujeito que está obrigado (necessidade deôntica) a realizar o evento descrito pelo predicado, no caso, "ajudar com a recuperação de seu quadro profissional". Em (2), o modal necesitar é empregado para reportar a obrigatoriedade de realização de um evento, no caso, "o trabalho diário na prevenção do risco de desastres". Pondera-se também que a leitura deôntica seja favorecida pela performatividade [+diretivo] do predicado sobre o qual o modal tem escopo de atuação, em questão, os predicados ayudar e trabajar.

Com base nas ocorrências (1) e (2), pode-se constatar que a construção necesitar+infinitivo permite interpretações modais deônticas. Nesse sentido, pondera-se que essa construção possa, conforme Hengeveld (2004), depois revisto e ampliado na Gramática DiscursivoFuncional (GDF) de Hengeveld e Mackenzie (2008), qualificar a modalidade deôntica a partir de duas orientações modais específicas: (i) uma modalidade deôntica orientada para o Participante, quando recai sobre um dado participante a obrigação, permissão ou proibição de realizar o evento descrito pelo predicado; ou (ii) uma modalidade deôntica orientada para o Evento, quando se descreve o estatuto objetivo de um evento em termos do que é entendido como obrigatório, permitido ou proibido.

\footnotetext{
${ }^{2}$ Exemplo retirado da Internet. Tradução livre: O senhor também precisa ajudar na recuperação de sua equipe. Uma reunião pós-emergência é essencial para deixar seu pessoal desabafar e ter certeza de que você entendeu o que aconteceu para que possa melhorar seu serviço da próxima vez. Porque haverá uma próxima vez. Disponível em: https://verificationhandbook.com/book_ es/chapter8.php. Acesso em: 08 set. 2020.

3 Exemplo retirado da Internet. Tradução livre: Precisa-se trabalhar na prevenção de riscos de desastres todos os dias, caso contrário, não teremos sucesso. Essa tarefa pode levar muitos anos, mas não os temos e temos que trabalhar juntos e com rapidez para alcançá-la "Mami Mizutori". Disponivel em: https://twitter.com/arisemx/status/1177227925642522624. Acesso em: 08 set. 2020.
} 
V. $11(2)$

1-21

maio-ago

2021

Portanto, o objetivo principal que motiva esta pesquisa é a de verificar como a construção perifrástica necesitar+infinitivo se comporta nas camadas que compõem o Nível Representacional como forma de expressão da modalidade deôntica. Assim sendo, a partir desse objetivo principal, pretende-se também: (i) analisar como o auxiliar modal necesitar atua como operador modal na expressão da modalidade deôntica em língua espanhola; e (ii) oferecer evidências empíricas em favor da postulação do seu comportamento modal deôntico, bem como os valores modais deônticos que essa construção pode instaurar. Para isso, a análise apoia-se no modelo teórico da GDF proposto por Hengeveld e Mackenzie (2008).

Nesse sentido, o modelo teórico da GDF permite que se faça: (i) uma abordagem top-down na acomodação do papel do falante na expressão da modalidade deôntica por meio da construção perifrástica necesitar+infinitivo, a partir do que é entendido ou imposto como regra e norma de conduta; e (ii) uma organização em níveis e camadas que facilita uma caracterização mais específica e pormenorizada da construção perifrástica necesitar+infinitivo empregada na instauração da modalidade deôntica.

Para cumprir com o objetivo principal desta pesquisa, este artigo foi organizado em quatro seções, além desta introdução e das considerações finais. As duas primeiras seções dizem respeito ao modelo teórico da GDF e à descrição da modalidade deôntica com base na hierarquização das camadas no Nível Representacional. Na sequência, está a seção em que se discorre sobre a construção perifrástica necesitar+infinitivo em língua espanhola. Posteriormente, apresenta-se a seção em que será feita a descrição e análise da construção modal necesitar+infinitivo como forma de expressão da modalidade deôntica, a partir de seu escopo de atuação nas camadas que compõem o Nível Representacional.

\section{A Gramática Discursivo-Funcional}

A GDF assume o pressuposto funcionalista de que as propriedades dos enunciados produzidos durante a interação comunicativa entre os Participantes (Falante e Ouvinte) podem ser adaptáveis às suas intenções e aos seus propósitos comunicativos, na medida em que eles pretendem alcançar um dado objetivo. Com base nesse postulado central da perspectiva funcionalista, a GDF se apresenta 
como um modelo teórico de gramática funcional, estruturando-se em níveis e camadas hierarquicamente ordenados e em progressão topdown (de cima para baixo).

Dessa forma, o modelo top-down da GDF permite que haja uma adequação pragmática (nível superior), em que este nível governa e condiciona a semântica, a morfossintaxe e a fonologia (níveis inferiores). Entendendo que essa organização descendente é uma condição fundamental para a existência de uma teoria gramatical, a GDF não trabalha a oração (clause) como unidade mínima de análise, mas o Ato Discursivo, que é definido como a menor unidade identificável de comportamento comunicativo. Portanto, as orações são apenas uma das opções das quais o Falante dispõe para desenvolver o seu discurso (na GDF, definido como o uso efetivo da língua em um contexto de produção específico).

Considerando a adequação pragmática, Hengeveld e Mackenzie (2008) definem a GDF como um modelo mais amplo de interação verbal, em que o Componente Gramatical está associado a outros três componentes não gramaticais, a saber: (i) o Componente Conceitual, que diz respeito às informações pragmáticas compartilhadas entre os Participantes, bem como às suas representações mentais, às suas conceitualizações sobre a realidade extralinguística e às suas intenções comunicativas que são relevantes para o ordenamento do evento de fala; (ii) o Componente Contextual, que se refere à descrição do conteúdo e da forma do discurso precedente, do contexto real perceptível em que ocorre o evento de fala e das relações sociais entre os Participantes; e (iii) o Componente de Saída, que diz respeito à conversão das informações provenientes do Componente gramatical em expressões acústicas (fala), simbólicas (sinais) e ortográficas (escrita).

Por sua vez, o Componente Gramatical está estruturado em níveis e camadas hierarquicamente ordenados, a saber: os Níveis Interpessoal, Representacional, Morfossintático e Fonológico.

O Nível Interpessoal é o responsável pelos aspectos pragmáticos das unidades linguísticas, captando as distinções de Formulação que dizem respeito à interação entre os Participantes, estando constituído pelas seguintes camadas: Movimento $(M)$ > Ato Discursivo (A) > Ilocução (F) $>$ Participantes $\left[\mathrm{P}_{1}-\right.$ Falante e $\mathrm{P}_{2}-$ Ouvinte $]>$ Conteúdo Comunicado (C) > Subato de Atribuição (T) > Subato de Referência (R). Por sua vez, o Nível Representacional é o responsável pela designação semântica das unidades linguísticas, compondo-se das seguintes camadas: Conteúdo 
V. $11(2)$

1-21

maio-ago

2021

Proposicional $(\mathrm{p})>$ Episódio $(\mathrm{ep})>$ Estado-de-coisas $(\mathrm{e})>$ Propriedade Configuracional $\left(f_{1}\right)>$ Propriedade lexical $\left(f_{2}\right)$. Especificamente, nestes dois níveis, ocorre a operação de Formulação.

O Nível Morfossintático é o responsável pelas representações estruturais das unidades linguísticas, a partir das informações que são fornecidas pelos dois níveis superiores, compondo-se das seguintes camadas: Expressão Linguística (Le) > Oração $(\mathrm{Cl})>$ Sintagma $(\mathrm{Xp})>$ Palavra (Xw) > Base (Xs) > Afixo (Aff). Por seu turno, o Nível Fonológico é o responsável pela produção prosódica das unidades linguísticas, a partir do input recebido dos três níveis que lhe são superiores, compondose das seguintes camadas: Enunciado (U) > Frase Entonacional (IP) > Frase Fonológica $(\mathrm{PP})>$ Palavra Fonológica $(\mathrm{PW})>$ Pé $(\mathrm{F})>$ Sílaba $(\mathrm{S})$. Designadamente, nestes dois níveis, ocorre a operação de Codificação.

Com base no modelo teórico da GDF, especificamente em relação aos níveis e às camadas que compõem o Componente Gramatical, a análise da modalidade deôntica será feita considerando tanto os aspectos semânticos (Nível Representacional) quanto os morfossintáticos (Nível Morfossintático) envolvidos na instauração da deonticidade por meio da construção perifrástica necesitar+infinitivo.

No tocante à modalidade deôntica, verifica-se que, na GDF, as distinções modais e o tratamento dado à categoria modalidade estão alocados no Nível Representacional, como se verá na seção seguinte.

\section{A modalidade deôntica na GDF}

No aparato teórico da GDF, a categoria modalidade é descrita e analisada com base em Hengeveld (1988) e Hengeveld (2004). Ainda que a GDF não apresente uma definição categórica acerca do conceito de modalidade, ${ }^{4}$ esta pode ser delimitada, conforme Hengeveld (1988), com base nas diferentes acepções semânticas que as unidades linguísticas podem apresentar na interação discursiva, a partir da: (i) caracterização da relação existente entre um participante e um evento e a potencialização de realização desse evento (modalidade inerente); (ii) avaliação objetiva do estatuto de realidade de um evento em termos dos conhecimentos sabidos e adquiridos sobre o mundo real (modalidade objetiva); e (iii) apreciação subjetiva do falante em relação ao seu comprometimento com a verdade de uma proposição (modalidade epistemológica).

4 Na seara da Linguística, a modalidade pode ser definida, conforme Palmer (1986), como a gramaticalização das opiniões e crenças subjetivas do falante. 
Em Hengeveld (2004), a modalidade passa a ser descrita e analisada a partir de dois parâmetros principais: (i) o domínio semântico, que diz respeito ao tipo de avaliação que se faz do enunciado modalizado; e (ii) a orientação modal, que diz respeito à parte do enunciado que é modalizada, ou seja, a perspectiva sobre a qual recai a modalidade.

Com base no primeiro parâmetro, Hengeveld (2004) divide a modalidade em cinco categorias: (i) modalidade facultativa, que diz respeito às capacidades e às habilidades inerentes ou adquiridas; (ii) modalidade epistêmica, que está relacionada aos conhecimentos e às crenças acerca do mundo real; (iii) modalidade evidencial, que se refere à fonte da informação que é veiculada no enunciado modalizado; (iv) modalidade volitiva, que diz respeito ao que é desejável ou indesejável; e (v) modalidade deôntica, que se trata do que é moralmente, legalmente e socialmente aceito em termos de regras e normas de conduta.

A partir do segundo parâmetro, Hengeveld (2004) especifica que a modalidade pode apresentar diferentes tipos de orientação: (i) para o Participante, que se trata da relação entre um participante (ou as propriedades) em um evento e a realização potencial desse evento; (ii) para o Evento, que se refere à descrição de um evento, mas sem que se faça uma avaliação subjetiva sobre o estatuto de realidade desse evento; e (iii) para a Proposição, que diz respeito à parte do enunciado que representa as visões e as crenças do falante, e concerne à especificação do grau de comprometimento do falante com a proposição que ele apresenta.

Com base na tipologia das modalidades proposta por Hengeveld (2004), Hengeveld e Mackenzie (2008) especificam que os diferentes tipos de modalidade (epistêmica, facultativa, volitiva e deôntica) ${ }^{5}$ podem ser delimitados com base em seu escopo de atuação nas camadas do Nível Representacional. Nesse sentido, as unidades linguísticas (operadores e modificadores) são descritas e analisadas a partir da categoria semântica que designam, podendo ser Conteúdos Proposicionais (p), Episódios (ep), Estados-de-Coisas (e) ou Propriedades Configuracionais (f).

Assim, as camadas nas quais a categoria modalidade pode operar são as: (i) do Conteúdo Proposicional, que se refere a construtos mentais, podendo ser factual, quando diz respeito aos conhecimentos e às crenças do mundo, ou não-factual, quando se trata de desejos ou expectativas em relação a um mundo imaginário; (ii) do Episódio,

${ }^{5} \mathrm{Na}$ GDF, a modalidade evidencial deixa de ser considerada um subtipo de modalidade, passando a ser entendida como uma categoria linguística, a Evidencialidade. 
V. $11(2)$

1-21

maio-ago

2021

que são conjuntos de Estado-de-Coisas tematicamente coerentes, já que revelam unidade ou continuidade de tempo (t), localização (l), e indivíduos (x), localizados em um tempo absoluto; (iii) do Estado-deCoisas, que envolvem eventos e estados com localização no tempo e no espaço e que podem ser avaliados em termos de seu estatuto de realidade, podendo ou não ocorrer em um intervalo de tempo relativo; e (iv) da Propriedade Configuracional, que são de natureza composicional, contendo uma combinação de unidades semânticas que não estabelecem uma relação hierárquica entre si.

Conforme Hengeveld e Mackenzie (2008), a modalidade deôntica pode operar na camada da Propriedade Configuracional e do Estado-de-Coisas. Assim sendo, os operadores modais deônticos podem ter um escopo de atuação sobre um predicado (interno à predicação), atuando, portanto, na camada da Propriedade Configuracional; ou uma predicação (predicados e seus argumentos), atuando, desse modo, na camada do Estado-de-Coisas.

Na camada da Propriedade Configuracional, a modalidade deôntica designa um participante que está obrigado, permitido ou proibido de se envolver no evento designado pelo predicado, como no exemplo: I must eat [Eu devo comer] (HENGEVELD; MACKENZIE, 2008, p. 213). Por sua vez, na camada do Estado-de-Coisas, a modalidade deôntica designa o estatuto objetivo de realização de um evento, em que este é entendido como obrigatório, permitido ou proibido a partir de um conjunto de regras e normas já estabelecidas, como no exemplo: One has to take off one's shoes here [É preciso tirar os sapatos daqui] (HENGEVELD; MACKENZIE, 2008, p. 176).

Com base em Hengeveld e Mackenzie (2008), constata-se que a modalidade deôntica pode apresentar três valores modais: (i) obrigação, o que deve ser feito (polaridade positiva); (ii) permissão, o que pode ser feito (polaridade positiva); e (iii) proibição, o que não deve ser feito ou o que não pode ser feito (polaridade negativa). Como se pode verificar, os valores modais deônticos apresentam estreita relação com a noção de polaridade. De acordo com os autores, a polaridade se mostra como uma categoria relevante na camada do Estado-deCoisas, concentrando-se, portanto, na positividade ou na negatividade da ocorrência de um evento. Assim sendo, a polaridade positiva reforça a necessidade (obrigação) e a possibilidade (permissão) deônticas, enquanto a polaridade negativa assevera a negação de necessidade e de possibilidade deônticas (proibição). 
Como se pode constatar, a modalidade deôntica opera nas camadas inferiores do Nível Representacional, estando a ela relacionados os valores modais de obrigação, permissão e proibição. No que diz respeito à construção perifrástica necesitar+infinitivo, ponderase que ela possa instaurar necessidade deôntica (obrigação) em língua espanhola, como se verá na seção seguinte.

\section{A construção perifrástica necesitar+infinitivo em língua espanhola}

Conforme Glowicka (2016), em língua espanhola, é possível encontrar um grupo específico de recursos léxicos (unidades linguísticas) que são capazes de expressar obrigação: são os chamados modalizadores deônticos, que manifestam a atitude do falante em relação ao ouvinte. Dessa forma, a modalidade deôntica pode ser instaurada por meio de adjetivos (necesario, preciso, etc.), verbos que denotam necessidade (necesitar), auxiliares modais (deber, tener que, haber que, etc.) ou adjetivos em função predicativa (es necesario, es preciso, etc.).

De acordo com Alvarado e Koza (2018), a modalidade deôntica pode ser instaurada por meio de diferentes unidades linguísticas (modalizadores), entre as quais os autores citam os auxiliares modais deber, tener que, haber que, etc., assim como a construção necesitar+infinitivo. Ao serem empregados esses verbos modais, a modalidade deôntica está relacionada, geralmente, aos valores de obrigação e necessidade, podendo o falante instaurar obrigações morais e/ou necessidades físicas, em que estas variam conforme a origem ou a causa (fonte da atitude modal) da deonticidade instaurada.

Para Martínez Díaz (2008), a construção perifrástica necesitar+infinitivo pode, em alguns contextos específicos, expressar necessidade deôntica (obrigação), podendo esta necessidade estar condicionada por fatores internos ao próprio indivíduo ou a terceiros, havendo, assim, a marcação de um agente verbal (expresso pelo modalizador) sobre quem recai a responsabilidade pela ação do verbo. Nos casos em que a necessidade deôntica é motivada por fatores externos, geralmente há a ocultação de um agente verbal, sendo marcado por meio de elementos linguísticos de impessoalização (como a partícula se), ou, quando há a explicitação de um sujeito sintático por meio das marcas de terceira pessoa do singular/plural, emprega-se a voz passiva.

Hernández (2006) especifica que a construção perifrástica necesitar+infinitivo pode expressar obrigação (necessidade deôntica) 
V. $11(2)$

1-21

maio-ago

2021

quando há controle [+controle] do sujeito sintático sobre a ação verbal. Em consonância com o autor, Hulle (2017) também esclarece que a construção perifrástica necesitar+infinitivo pode se comportar como uma perífrase obrigativa quando o agente responsável pela ação verbal tem controle sobre o evento, como nos exemplos: Juan necesita presentar el carné [João precisa apresentar a carteira de motorista] e Juan necesita ler la carta [João precisa ler a carta] (HULLE, 2017, p. 11).

Para Rigat (2004), há uma distinção modal no uso entre a forma plena do verbo necesitar e a construção perifrástica necesitar+infinitivo, em que aquela pode expressar volição, ou seja, instaura modalidade volitiva, ${ }^{6}$ enquanto esta instaura modalidade deôntica, ao expressar o valor modal de obrigação, como nos exemplos de Rigat (2004, p. 623): El cocinero necesita la sal y la pimienta [O cozinheiro necessita do sal e da pimenta] (modalidade volitiva) e El cocinero necesita beber agua [O cozinheiro precisa beber água] (modalidade deôntica).

Ainda em relação a essas distinções modais, Rodríguez (2011) estabelece que a construção necesitar+que também se distingue da forma necesitar+infinitivo, em que esta expressa obrigação (modalidade deôntica), enquanto aquela é empregada para expressar volição (modalidade volitiva), ao manifestar o desejo do falante, especificamente quando este instiga o ouvinte a realizar uma determinada ação, como no exemplo: Cardona: - Eso, sí, a mí no gusta que me huevoneen, así que si va a estar conmigo necesito que se ponga bien seriecita y que deje de estar picando por aquí y por acá. Catalina: - Síclaro, por mí no hay ningún problema [Cardona: - Isso sim, eu não gosto de ser tratado como uma coisa, então, se vai ficar comigo, eu preciso que fique muito séria e pare de ciscar aqui e acolá. Catalina: - Sim, claro, por mim não tem problema] (RODRÍGUEZ, 2011, p. 28).

Em consonância com Rodríguez (2011), Rossowová (2016) também estipula que a construção necesitar+que apresenta uma leitura volitiva, especificamente nos contextos em que se expressam pedidos oriundos dos desejos do falante, em que a volição instaurada se qualifica como uma asserção das suas necessidades pessoais, como nos exemplos: Pero, ante todo, necesito que me seques estas ropas [Mas, antes, preciso que você seque estas roupas] e Necesito que te quedes [Eu quero que você fique] (ROSSOWOVÁ, 2016, p. 105106).

${ }^{6}$ Para Hengeveld (2004), a modalidade volitiva é relativa ao que é desejável ou indesejável por parte do falante ou de outro indivíduo descrito pelo predicado. 
Como se pode verificar, a construção perifrástica necesitar+infinitivo é empregada para expressar necessidade deôntica (obrigação). Nesse sentido, na seção seguinte, será descrito e analisado o seu comportamento nas camadas que compõem o Nível Representacional como forma de expressão da modalidade deôntica.

\section{A atuação da construção perifrástica necesitar+infinitivo nas camadas do Nível Representacional para a expressão da modalidade deôntica}

Partindo do pressuposto de que a construção perifrástica necesitar+infinitivo pode instaurar necessidade deôntica (obrigação), pondera-se que o verbo auxiliar necesitar, nessa construção, possa atuar como um operador de modalidade deôntica, ao incidir sobre predicados e predicações. Para isso, foram selecionados e analisados diferentes usos dessa construção perifrástica em amostras de língua que foram retiradas da Internet, tais como notícias, blogs, fóruns de debate, websites de faculdades e universidades, etc., e produzidas por falantes nativos de espanhol.

Dessa forma, será verificado, nesta seção, alguns aspectos semânticos e morfossintáticos que possam delimitar o operador necesitar como auxiliar modal deôntico, a saber: (i) a camada em que atua a construção perifrástica necesitar+infinitivo; (ii) o tipo de sujeito sintático [ \pm humano]; (iii) a controlabilidade do evento [ \pm controle] sobre o qual incide a deonticidade instaurada; (iv) os valores modais expressos por meio da construção perifrástica necesitar+infinitivo; e (v) a polaridade do enunciado modalizado.

Em relação à camada de atuação da construção perifrástica necesitar+infinitivo, verifica-se que ela pode atuar nas camadas da Propriedade Configuracional e do Estado-de-Coisas, como se pode constatar, respectivamente, nas ocorrências (3) e (4):

(3) Te dejamos esta lista de imprescindibles que una estudiante necesita llevar a la universidad. ${ }^{7}$

(4) Se necesita llevar la tarjeta actual para hacer un duplicado. ${ }^{8}$

\footnotetext{
7 Exemplo retirado da Internet. Tradução livre: Deixamos para você esta lista de itens essenciais que uma estudante precisa levar para a universidade. Disponível em: https://www. residenciainmaculadavitoria.com/que-llevar-a-la-residencia/. Acesso em: 09 set. 2020.

${ }^{8}$ Exemplo retirado da Internet. Tradução livre: Você precisa trazer o cartão atual para fazer uma cópia do cartão. Disponível em: https://atencionalcliente.movistar.es/pregunta-cliente/ se-necesita-llevar-la-tarjeta-actual-para-hacer-un-duplicado/. Acesso em: 09 set. 2020.
} 
V. $11(2)$

1-21

maio-ago

2021

Em (3), a modalidade deôntica opera na camada da Propriedade Configuracional, em que recai sobre o participante designado pelo predicado (una estudiante) a obrigação de realizar o evento contido no enunciado modalizado, no caso, levar os itens obrigatórios para a universidade. Por sua vez, em (4), a modalidade deôntica opera na camada do Estado-de-Coisas, em que se reporta, por meio da partícula de impessoalização se, a necessidade deôntica de concretização de um evento, no caso, a obrigação de levar o cartão atual do cliente para que se possa fazer uma cópia.

Verifica-se também que, em (3), o auxiliar modal necesitar incide sobre um predicado (llevar), cuja orientação modal deôntica está voltada para o Participante, enquanto, em (4), sobre uma predicação (llevar la tarjeta), cuja orientação modal deôntica está qualificada para o Evento. Nessas camadas inferiores, a modalidade deôntica é entendida como objetiva [ +objetiva], sem que o falante faça uma avaliação subjetiva sobre a obrigação instaurada por meio de alguma unidade linguística que expresse seu próprio material cognitivo.

No entanto, para além do que é predisposto por Hengeveld e Mackenzie (2008) na GDF, a modalidade deôntica pode ainda operar na camada do Episódio, conforme Olbertz (2017). Segundo a autora, nessa camada, a modalidade deôntica é de natureza avaliativa, em que o falante faz uma apreciação subjetiva [+subjetiva] sobre um evento anterior ao evento de fala, avaliando-o como sendo necessário (necessidade deôntica), como neste exemplo citado pela autora: Tenían que...nada más que poner esas fábricas al mismo tiempo que se las ponen...haber hecho algo para que no perjudicara al río (OLBERTZ, 2017, p. 12). ${ }^{9}$ Segundo a autora, nesse exemplo, a modalidade deôntica é de natureza avaliativa, em que há a combinação de uma forma imperfeita do pretérito no auxiliar modal (tenían que) e do passado relativo ao verbo no infinitivo (haber hecho) indicando, assim, a contrafactualidade do evento, ou seja, o evento descrito no Estado-de-Coisas é anterior ao momento de fala e que não ocorreu. Conforme Hengeveld e Mackenzie (2008), um único Estado-de-Coisas pode configurar em um Episódio, desde que aquele esteja sob o escopo de um tempo absoluto. No exemplo citado pela autora, o tempo absoluto é marcado pelo falante, ao explicitar que as fábricas foram colocadas ao mesmo tempo sob o leito do rio (evento anterior ao da avaliação subjetiva do falante).

9 Tradução livre: Eles tinham que ... apenas montar essas fábricas ao mesmo tempo em que foram colocadas ... ter feito algo para que não prejudicasse o rio. 
Dessa forma, pondera-se que a construção perifrástica necesitar+infinitivo também possa operar na camada do Episódio e, assim, expressar modalidade deôntica subjetiva, especificamente quando esta apreciação recai sobre um sujeito em particular, como se pode averiguar na ocorrência (5):

(5) Qué triste ver la destrucción de la familia de Gedeón (Yerubaal). Creo que él necesitaba haber leído el libro Él y Ella y El Libro para Padres de Familia de Nicky y Sila Lee y haber trabajado un poco más en esas áreas de su vida. ${ }^{10}$

Em (5), o falante faz uma avaliação subjetiva, o que é reforçado pelo operador epistêmico creo, que opera na camada do Conteúdo Proposicional, sobre a obrigação que ele avalia que deveria ter sido imposta ao sujeito sintático (él) expresso pelo auxiliar modal necesitar (necesitaba), em relação ao dever de ter lido os livros Él y Ella e Padres de Familia de Nicky y Sila Lee e ter trabalhado um pouco mais nessas áreas da sua vida (as questões familiares), o que poderia ter evitado que a família do indivíduo tivesse sido destruída. A avaliação subjetiva do falante, em (5), recai sobre um evento que é anterior ao momento de fala (a destruição da família do sujeito sintático indicado pelo auxiliar modal), explicitando, assim, que o evento avaliado está sob o escopo de um tempo absoluto. Nesse caso, também há a combinação de uma forma imperfeita do pretérito no auxiliar modal (necesitaba) e do passado relativo ao verbo no infinitivo (haber leído e haber trabajado), indicando, assim, a contrafactualidade do evento, ou seja, o evento descrito no Estado-de-Coisas (que integra o Episódio) é anterior ao momento de fala e que não ocorreu.

Em relação ao tipo de sujeito sintático [ \pm humano] expresso pelo modal, pondera-se que a animacidade [+humano] favorece que a modalidade deôntica opere na camada da Propriedade Configuracional, enquanto a inanimacidade [-humano] faz com que a modalidade deôntica atue na camada do Estado-de-Coisas, quando instaurada por meio da construção perifrástica necesitar+infinitivo, como se pode constatar, respectivamente, nas ocorrências (6) e (7):

${ }^{10}$ Exemplo retirado da Internet. Tradução livre: É muito triste ver a destruição da família de Gideão (Yerubaal). Acho que ele precisava ter lido Él y Ella e o livro para Padres de Familia de Nicky y Sila Lee, e ter trabalhado um pouco mais nessas áreas de sua vida. 
V. $11(2)$

1-21

maio-ago

2021

(6) "El poder cumplir con los tiempos de entrega establecidos es muy importante para las empresas dedicadas al transporte. Al incluir limitaciones de tiempo en el Driver's Fuel Challenge hace que este campeonato sea lo más parecido al día a día de los conductores. Para obtener el triunfo el conductor necesita conducir con una excelente planificación y optimizando el consumo de combustible" afirma Ricard Fritz, Senior Vicepresidente de Producto y Ventas de Vehículos en Volvo Trucks. ${ }^{11}$

(7) Los sensores de temperatura usualmente necesitan ser calibrados con regularidad para garantizar su correcto funcionamiento. ${ }^{12}$

Em (6), a modalidade deôntica opera na camada da Propriedade Configuracional, em que a construção perifrástica necesitar+infinitivo é empregada para manifestar a obrigação que recai sobre o participante designado pelo predicado (el conductor), que é animado [+humano], de realizar o evento, no caso, dirigir de forma otimizada para que se economize combustível. Por seu turno, em (7), a modalidade deôntica opera na camada do Estado-de-Coisas, em que a construção perifrástica necesitar+infinitivo é utilizada para se referir à obrigatoriedade de concretização do evento, em questão, que os sensores de temperatura, que é o sujeito sintático expresso pelo modal e inanimado [-humano], sejam calibrados periodicamente para que eles possam trabalhar de forma eficiente.

No entanto, na camada do Estado-de-Coisas, é plenamente possível, em alguns contextos específicos, que o sujeito sintático expresso pelo operador modal necesitar seja animado [+humano], necessariamente quando se tratar de um sujeito que irá sofrer a ação verbal, como na ocorrência (8):

\footnotetext{
${ }^{11}$ Exemplo retirado da Internet. Tradução livre: "Cumprir os prazos de entrega estabelecidos é muito importante para as empresas que se dedicam ao transporte. Ao incluir limitações de tempo no Driver's Fuel Challenge, torna este campeonato o que há de mais próximo do dia a dia dos motoristas. Para ter sucesso, o motorista precisa dirigir com excelente planejamento e otimização do consumo de combustível ", afirma Ricard Fritz, vice-presidente sênior de vendas de produtos e veículos da Volvo Trucks. Disponível em: https://peruconstruye.net/2018/11/16/ drivers-fuel-challenge-de-volvo-tiene-nuevo-ganador/. Acesso em: 09 set. 2020.

${ }^{12}$ Exemplo retirado da Internet. Tradução livre: Sensores de temperatura geralmente precisam ser calibrados regularmente para garantir a operação correta. Disponível em: <http://www. solucionesfmk.com/servicios/calibraciones.php>. Acesso em: 09 set. 2020.
} 
(8) Los niños necesitan ser consolados para tener un buen desarrollo emocional. ${ }^{13}$

Em (8), o sujeito sintático (los niños) expresso pelo modal necesitar é animado [+humano], porém não se refere a um participante que irá executar o evento, mas quem irá sofrer a ação designada pelo verbo (consolar), nesse caso, o sujeito sintático é paciente [+paciente]. Assim sendo, a modalidade deôntica, ainda que seja instaurada com a animacidade [+humano] do sujeito sintático, opera na camada do Estado-de-Coisas e não na camada da Propriedade Configuracional. Isso pode ser explicitado pela possibilidade da construção perifrástica necesitar+infinitivo ser substituída pelo adjetivo em posição predicativa es necesario, na expressão de modalidade deôntica, a saber: Es necesario que los niños sean consolados para tener un buen desarrollo emocional.

No que diz respeito à controlabilidade do evento, ponderase que, quando o Estado-de-Coisas é controlado [+controle], há a instauração de modalidade deôntica, haja vista que, conforme Neves (2010), esse é um dos traços semânticos característicos desse subtipo modal. No entanto, para os casos em que o Estado-de-Coisas não é controlado [-controle], há a instauração de modalidade volitiva, quando se emprega a construção perifrástica necesitar+infinitivo, como se pode constatar nas ocorrências (9) e (10):

(9) Mi nombre es Deilyn soy una adolescente que acaba de terminar la secundaria y estoy un poco interesada en la Psicologia y quisiera saber que es lo que necesito estudiar primero para ser Psicóloga pero a mi no me gusta nada de medicina, enfermería y cosas así, pero si me gusta mucho ayudar a las personas cuando enfrenta un problema, escucharlas y darles una solución a sus problemas. ${ }^{14}$

\footnotetext{
${ }^{13}$ Exemplo retirado da Internet. Tradução livre: As crianças precisam ser consoladas para terem um bom desenvolvimento emocional. Disponível em: https://www.edurespeta.com/los-ninosnecesitan-ser-consolados-para-tener-un-buen-desarrollo-emocional/. Acesso em: 09 set. 2020.

${ }^{14}$ Exemplo retirado da Internet. Tradução livre: Meu nome é Deilyn, sou uma adolescente que acabou de terminar o ensino médio e estou um pouco interessada em Psicologia e gostaria de saber o que eu preciso estudar primeiro para ser psicóloga, mas não gosto de medicina, enfermagem e coisas assim. Mas sim, eu realmente gosto de ajudar as pessoas quando elas enfrentam um problema, escutá-las e dar a elas uma solução para os seus problemas. Disponível em: https://www.emagister.com/blog/que-tengo-que-estudiar-para-ser-psicologo/. Acesso em: 09 set. 2020.
} 
V. $11(2)$

1-21

maio-ago

2021
(10) No es que quiera morir ..yo amo la vida y soy joven es solo que estoy evitando algo q va. a pasar q es muy dañino para mi y bueno quiero saber una manera rápida y segura .este sábado $y$ domingo necesito estar enfermo con fiebre y dolor d cuerpo pero no morir ayuda!!!!!!!!!15

Em (9) e (10), a construção perifrástica necesitar+infinitivo é empregada para instaurar modalidade. No entanto, essa construção instaura distintos tipos de modalidade, ainda que estas operem na camada da Propriedade Configuracional. Em (9), instaura-se a modalidade deôntica, cuja leitura deôntica é favorecida pela controlabilidade do evento [+controle], em que recai sobre o participante designado pelo predicado (yo) a obrigação de estudar alguns conteúdos obrigatórios para ingressar na faculdade de Psicologia. Por sua vez, em (10), instaurase a modalidade volitiva, cuja leitura volitiva é favorecida pela nãocontrolabilidade do evento [-controle], em que o participante descrito pelo predicado (yo) manifesta o desejo de ficar doente, com febre e dor pelo corpo. ${ }^{16}$

Em relação aos valores modais expressos pela construção perifrástica necesitar+infinitivo e a polaridade do enunciado modalizado, é possível verificar que há relação entre essas categorias de análise. Nesse sentido, a polaridade positiva instaura o valor modal de obrigação (necessidade deôntica - polaridade positiva), enquanto a polaridade negativa instaura o valor de derrogação ${ }^{17}$ (negação de necessidade deôntica - polaridade negativa), como se pode averiguar nas ocorrências (11) e (12):

\footnotetext{
${ }^{15}$ Exemplo retirado da Internet. Tradução livre: Não é que eu queira morrer ... Eu amo a vida e sou jovem, é só que estou evitando algo que vai. que aconteça que é muito prejudicial para mim e bom quero conhecer um caminho rápido e seguro neste sábado e domingo preciso estar doente com febre e dores no corpo mas não morrer ajuda! Disponível em: https://espanol. answers.yahoo.com/question/index?qid=20140811101634AAMb4H9. Acesso em: 09 set. 2020.

${ }_{16}$ Baseando-se em Dik (1997), acredita-se que a leitura deôntica e volitiva seja também favorecida pelo tipo de Estado-de-Coisas que está sob o escopo de atuação do modalizador necesitar+infinitivo, em que a modalidade deôntica incide sobre Estado-de-Coisas de Ação [+controle, +dinamismo], enquanto a modalidade volitiva incide sobre Estado-de-Coisas de Processo [-controle, +dinamismo].

${ }^{17}$ De acordo com Fernández Martín (2014), a negação de necessidade ou a derrogação (exención, em espanhol) se trata de uma negação de obrigação externa ou interna excessivamente fraca, haja vista que é solicitado que o sujeito não realize o ato deôntico, mas poderia fazê-lo, caso sentisse necessidade ou desejo de concretizar o evento, não estando obrigado a isso, como no exemplo: No tienes que abrir la puerta [Você não precisa abrir a porta] (FERNÁNDEZ MARTÍN, 2014, p. 81).
} 
(11) Algunas personas tratan de presentar las indulgencias como el perdón de una deuda por los pecados cometidos, pero una indulgencia no es el perdón de una deuda, sino el pago de la deuda. En general, para obtener las indulgencias, se necesita cumplir determinadas condiciones y realizar determinadas obras. El creyente necesita cumplir con las siguientes condiciones. ${ }^{18}$

(12) La población general sana no necesita llevar mascarilla ante el \#coronavirus, salvo si cuidas a un enfermo o eres sanitario. jSé responsable! Otros colectivos sí la necesitan.19

Em (11) e (12), a modalidade deôntica opera na camada da Propriedade Configuracional, haja vista que sobre o participante designado pelo predicado recai, respectivamente, a obrigação e a derrogação de realizar o evento. Em (11), a construção perifrástica necesitar+infinitivo é empregada para instaurar a necessidade deôntica sobre o participante (el creyente), que está obrigado a cumprir algumas exigências caso deseje receber o perdão de seus pecados. Por sua vez, em (12), a construção perifrástica necesitar+infinitivo é utilizada para instaurar a negação de necessidade deôntica sobre o participante (la población general sana), que não está obrigado a usar máscara para se proteger do coronavírus, mas poderia fazê-lo, caso desejasse. A exceção a essa recomendação está restrita aos casos em que as pessoas sãs devam, por alguma razão, cuidar ou entrar em contato com pessoas acometidas pelo coronavírus.

Constata-se também que os valores modais de obrigação (necessidade deôntica - polaridade positiva) e derrogação (negação de necessidade deôntica - polaridade negativa) podem ser instaurados com a modalidade deôntica operando na camada do Estado-de-Coisas, como se pode averiguar nas ocorrências (13) e (14):

\footnotetext{
18 Exemplo retirado da Internet. Tradução livre: Algumas pessoas tentam apresentar indulgências, como o perdão de uma dívida pelos pecados cometidos, mas uma indulgência não é o perdão de uma dívida, mas o pagamento da dívida. Em geral, para obter indulgências, você precisa atender a certas condições e realizar determinados trabalhos. O crente precisa atender às seguintes condições. Disponível em: https://sfcatolico.org/blog/cuales-son-los-requisitospara-obtener-indulgencias. Acesso em: 09 set. 2020.

${ }^{19}$ Exemplo retirado da Internet. Tradução livre: A população saudável em geral não precisa usar máscara contra o \#coronavírus, exceto se você cuidar de uma pessoa doente ou trabalhar na área de saúde. Seja responsável! Outros grupos precisam disso. Disponível em: https://lolleria. org.es/es/la-poblacion-general-sana-no-necesita-llevar-mascarilla-ante-el-coronavirussalvo-si-cuidas-a-un-enfermo-o-eres-sanitario/. Acesso em: 09 set. 2020.
} 
V. $11(2)$

1-21

maio-ago

2021

(13) El alcalde del distrito de Pimentel, provincia de Chiclayo, José Francisco Gonzáles Ramírez, indicó a RPP Noticias que gestionará ante una empresa privada la adquisición de estos modernos equipos para proteger de los rayos solares a los veraneantes. "Es una propuesta que estamos evaluando, lo elevaremos a concejo distrital y gestionaremos el presupuesto necesario para la compra. Sin duda, el sol está quemando mucho y se necesita cuidar a los niños", indicó. ${ }^{20}$

(14) Una ciudad griega en la que no se necesita llevar dinero en el bolsillo. La ciudad de Volos ha decidido implementar una nueva moneda basada en el viejo sistema del trueque. La iniciativa popular ha crecido hasta convertirse en una red de más de 800 miembros. ${ }^{21}$

Em (13) e (14), a modalidade deôntica opera na camada do Estado-de-Coisas, pois se reporta, respectivamente, por meio da impessoalização com a partícula se, a obrigação e a derrogação de realizar um evento, manifestando, dessa forma, o estatuto objetivo do Estado-de-Coisas. Em (13), a construção perifrástica necesitar+infinitivo é empregada para instaurar a necessidade deôntica (obrigação) de concretização do evento, no caso, cuidar das crianças para evitar insolação. Em (14), a construção perifrástica necesitar+infinitivo é utilizada para instaurar a negação de necessidade deôntica (derrogação) de concretização do evento em questão: levar dinheiro no bolso para efetuar compras, ainda que o sujeito possa fazê-lo, caso deseje.

\section{Considerações finais}

Com o objetivo de analisar a atuação da construção perifrástica necesitar+infinitivo nas camadas que compõem o Nível Representacional,

\footnotetext{
${ }^{20}$ Exemplo retirado da Internet. Tradução livre: O prefeito do distrito de Pimentel, na província de Chiclayo, José Francisco Gonzáles Ramírez, disse ao RPP Notícias que vai negociar com uma empresa privada a aquisição desses modernos equipamentos para proteger os veranistas dos raios solares. "É uma proposta que estamos avaliando, vamos levantar para a câmara distrital e vamos administrar o orçamento necessário para a compra. Sem dúvida, o sol está queimando muito e é preciso cuidar das crianças", disse. Disponível em: https://rpp.pe/peru/actualidad/ evaluan-colocar-solmaforos-en-pimentel-por-alta-radiacion-solar-noticia-658465. Acesso em: 09 set. 2020.

${ }^{21}$ Exemplo retirado da Internet. Tradução livre: Uma cidade grega onde você não precisa carregar dinheiro no bolso. A cidade de Volos decidiu implementar uma nova moeda baseada no antigo sistema de troca. A iniciativa popular cresceu e se tornou uma rede de mais de 800 membros. Disponível em: https://www.elmostrador.cl/noticias/mundo/2012/04/16/una-ciudad-griegaen-la-que-no-se-necesita-llevar-dinero-en-el-bolsillo/. Acesso em: 09 set. 2020.
} 
foram propostas algumas categorias de análise, a saber: a camada em que atua a construção perifrástica necesitar+infinitivo, o tipo de sujeito sintático, a controlabilidade do evento, os valores modais expressos por meio da construção perifrástica necesitar+infinitivo e a polaridade do enunciado modalizado. Essas categorias de análise foram pautadas no intuito de qualificar a atuação do auxiliar modal necesitar a partir de seu escopo de atuação sobre predicados e predicações (predicados e seus argumentos).

As análises revelaram que a construção perifrástica necesitar+infinitivo pode operar nas camadas da Propriedade Configuracional, quando recai sobre um dado participante a necessidade deôntica (obrigação) de realizar um evento, e do Estado-de-Coisas, quando se reporta a necessidade deôntica (obrigação) de concretização de um evento, que é entendido como obrigatório. Para além do que é pré-disposto na GDF, verificou-se que a modalidade deôntica pode operar também na camada do Episódio por meio da construção perifrástica necesitar+infinitivo, nos casos em que o falante faz uma avaliação subjetiva sobre um evento que é anterior ao momento de fala, mas entendido por ele como sendo necessário (necessidade deôntica).

Averiguou-se que, na camada da Propriedade Configuracional, o sujeito sintático expresso pelo modal tende a ser animado [+humano], enquanto na camada do Estado-de-Coisas, ele pode ser tanto inanimado [-humano] quanto animado [+humano], sendo que, neste último caso, o sujeito sintático sofre a ação verbal [+paciente]. No que tange à controlabilidade do evento, a construção perifrástica necesitar+infinitivo instaura a modalidade deôntica sobre eventos entendidos como controlados [+controle], enquanto o não controle [-controle] do evento favorece a instauração de modalidade volitiva.

No que diz respeito aos valores modais expressos e a polaridade do enunciado modalizado, foi constatado que a polaridade positiva está relacionada à instauração de necessidade deôntica (obrigação), enquanto a polaridade negativa está relacionada à instauração de negação de necessidade deôntica (derrogação). Ambos os valores modais expressos por meio da construção perifrástica necesitar+infinitivo podem operar tanto na camada da Propriedade Configuracional quanto do Estado-deCoisas.

Esses resultados, ainda que não estejam assentados na descrição de um corpus específico, já que foram empregadas amostras de língua retiradas da Internet, revelam certa adequação com o modelo teórico da 
V. $11(2)$

1-21

maio-ago

2021

GDF, na medida em que se analisou a atuação da construção perifrástica necesitar+infinitivo nas camadas que compõem o Nível Representacional, revelando, assim, os aspectos semânticos e morfossintáticos envolvidos na instauração da modalidade deôntica por meio dessa construção.

\section{Referências}

ALVARADO, C.; KOZA, W. La subordinación completiva del español: una aproximación funcional-tipológica. Revista Lenguas Modernas, n. 52, 2018, p. 11-34. Disponível em: https://lenguasmodernas.uchile.cl/index.php/LM/ article/view/52842/55438. Acesso em: 09 set. 2020.

DIK. C. S. The Theory of Funcional Grammar. Berlin/ New York: Mounton de Gruyter, 1997.

FERNÁNDEZ MARTÍN, P. La modalidad deóntica en las paremias españolas: entre el deber, el poder y el haber de hacer. Revista Paremia, v. 23, 2014, p. 7989. Disponível em: https://cvc.cervantes.es/LENGUA/paremia/pdf/023/008 fernandez.pdf. Acesso em: 09 set. 2020.

GLOWICKA, M. Formas de expresión de la obligación en español y en polaco: problemática de su traducción. Revista Itinerarios, n. 24, 2016, p. 61-78. Disponível em: http://itinerarios.uw.edu.pl/wp-content/uploads/2016/12/4 Monika-Glowicka.pdf. Acesso em: 09 set. 2020.

HENGEVELD, K. Illocution, mood and modality in a functional grammar of Spanish. Journal of Semantics, v.3, n. 6, 1988. p. 227-269. Disponível em: https://pure.uva.nl/ws/files/2114217/27913_hengeveld1988b.pdf. Acesso em: 13 maio 2020.

HENGEVELD, K. Illocution, mood, and modality. In: BOOIJ, G.; LEHMANN, C.; MUGDAN, J. Morphology: a handbook on inflection and word formation. v. 2. Berlin: Mouton de Gruyter, 2004, p. 1190-1201.

HENGEVELD, K.; MACKENZIE, J. L. Functional Discourse Grammar: a typologically based theory of language structure. Oxford: Oxford Linguistics, 2008.

HERNÁNDEZ, J. G. C. Perífrasis verbales en formación en el español de México. 2006. 59f. Monografia (Licenciatura em Linguística) - Departamento de Filosofia, Universidade Autônoma Metropolitana, Cidade do Mexico, 2006. Disponível em: http://148.206.53.233/tesiuami/UAMI13519.pdf. Acesso em: 09 set. 2020.

HULLE, S. V. Las perífrasis incoativas en español: Un estudio empírico de romper a + infinitivo. 2017. 94f. Dissertação (Mestrado em Língua e Literatura) - Programa de Pós-Graduação em Língua e Literatura, Universidade de Filosofia, Noruega, 2017. Disponível em: https://lib.ugent.be/fulltxt/ RUG01/002/349/062/RUG01-002349062_2017_0001_AC.pdf. Acesso em: 09 set. 2020.

MARTÍNEZ DÍAZ, E. La expresión de la modalidad de obligación en el Corpus del español conversacional de Barcelona y su Área Metropolitana (2001). In: MORENO SANDOVAL, A. (Org.). El valor de la diversidad (meta)lingüística: 
Actas del VIII Congreso de Lingüística General. Madrid: Editorial Universidad Autónoma, 2008, p. 1-20.

NEVES, Maria Helena de Moura. Texto e gramática. São Paulo: Contexto, 2010.

OLBERTZ. H. Periphrastic expressions of non-epistemic modal necessity in Spanish: a semantic description. Web Papers in Functional Discourse Grammar, n. 90, 2017, p. 1-25. Disponível em: <https://pure.uva.nl/ws/ files/25728515/WP_FDG_90.pdf>. Acesso em: $27 \mathrm{fev.} 2017$.

PALMER, F. R. Mood and Modality. Cambridge: Cambridge University Press, 1986.

RIGAT, M. V. Una clasificación perceptiva de la categoría verbo. Revista de Estudios de Lingüística: El Verbo, 2004, p. 615-628. Disponível em: https:// rua.ua.es/dspace/bitstream/10045/9801/1/ELUA_Anexo2_30.pdf. Acesso em: 09 set. 2020.

RODRÍGUEZ, A. G. Relaciones jerarquizadas en un serial televisivo: el uso del imperativo y otros recursos lingüísticos. Logos: Revista de Lingüística, Filosofía y Literatura, v. 21, n. 1, 2011, p. 16-39. Disponível em: https:// revistas.userena.cl/index.php/logos/article/view/153/160. Acesso em: 09 set. 2020.

ROSSOWOVÁ, L. Cortesía verbal en el español del siglo XIX. 2016. $195 \mathrm{f}$. Dissertação (Mestrado em Letras e Línguas Românicas) - Programa de PósGraduação em Filosofia da Linguagem, Universidade de Masarykova, República Tcheca, 2016. Disponível em: https://is.muni.cz/th/nyvac/Dizertacni_pracefinalni_verze.pdf. Acesso em: 09 set. 2020. 